Keywords: Affect; Emotions; Guilt; Job Design; Job Performance

\author{
Guilt by Design: Structuring Organizations to Elicit Guilt as an Affective Reaction to Failure \\ Vanessa K. Bohns, University of Waterloo \\ Francis J. Flynn, Stanford University
}

Published in Organization Science

\begin{abstract}
In this article, we outline a model of how organizations can effectively shape employees' affective reactions to failure. We do not suggest that organizations eliminate the experience of negative affect following performance failures - instead, we propose that they encourage a more constructive form of negative affect (guilt) instead of a destructive one (shame). We argue that guilt responses prompt employees to take corrective action in response to mistakes, while shame responses are likely to elicit more detrimental effects of negative affect. Further, we suggest that organizations can play a role in influencing employees' discrete emotional reactions to the benefit of both employees and the organization. We describe the necessary antecedents for encouraging guilt responses without simultaneously eliciting shame. Essentially, employees are more likely to experience guilt (but not shame) if they feel they had control over a specific negative event and the event resulted in a negative outcome for others. Given these necessary preconditions, we identify a set of organizational characteristics - autonomy, specificity of performance feedback, and outcome interdependence - that can be modified to make the experience of guilt more likely than that of shame in the workplace. The ethical and practical limits of shaping employees' emotional experiences within a negative affective domain are also addressed.
\end{abstract}

\title{
Acknowledgements
}

We would like to thank Stéphane Côté and Sanford DeVoe for their helpful comments.

\author{
Corresponding Author: \\ Vanessa K. Bohns \\ Department of Management Sciences \\ University of Waterloo \\ 200 University Avenue West \\ Waterloo, Ontario, Canada N2L 3G1 \\ vbohns@uwaterloo.ca
}




\section{Guilt by Design: Structuring Organizations to Elicit Guilt as an Affective Reaction to Failure}

When employees fail to perform their tasks, or perform them poorly, they typically experience a form of negative emotion (e.g., Carver \& Scheier 1990). Some of these negative emotions may be adaptive and some maladaptive. In particular, guilt is an adaptive affective response to failure, and shame is not. Though related, guilt and shame have important distinctions. Shame tends to be associated with destructive actions, such as withdrawal, hostility, and resistance (Dickerson, Gruenewald \& Kemeny 2004; Tangney, 1991; Tangney, Wagner, Fletcher \& Gramzow 1992), whereas guilt tends to inspire more constructive actions, such as engagement, apologizing, and reparation (Tangney, 1991; Tangney \& Dearing, 2002; Tangney, Wagner, Fletcher \& Gramzow 1992). In this article, we outline a model of how organizations can shape employees' discrete affective reactions to performance failure. Specifically, we posit that several workplace features should be enhanced not to avoid negative affect, but rather to promote a specific form of negative affect that tends to be constructive (guilt) without simultaneously fostering another form of negative affect that tends to be destructive (shame).

Conventional wisdom suggests that organizations should avoid making their employees feel bad. However, it is unrealistic to expect employees to feel good in response to performance failure. Noting this, organizations must be concerned with the relative impact that discrete negative emotions can have on an employee's subsequent motivation and performance. We argue that feeling guilty in response to performance failures at work is far superior to feeling ashamed. Shame leads people to make attributions about their core abilities that can sabotage their motivation to correct mistakes and undermine their confidence to make subsequent improvements. Conversely, employees who feel guilty are more likely to identify the exact maladaptive behaviors that led to poor performance outcomes than to blame stable, unfavorable attributes of themselves (e.g., Lewis 1971; Tangney, Stuewig, \& Mashek 2007; Tracy \& Robins 2006). Although both feelings are unpleasant, guilt is less demoralizing than shame, and thus, guilt is more likely to inspire employees to rectify their mistakes rather than dwelling on them or reacting in other unconstructive ways (Leith \& Baumeister 1998). 
To some extent, the advantages offered by guilt over shame in reacting to setbacks have been documented by previous research on individual differences in guilt- and shame-proneness (e.g., Tangney \& Dearing 2002). It is therefore a relatively small leap to suggest that such advantages may exist in the professional domain. A more significant theoretical issue is how environmental characteristicsparticularly job characteristics — can influence the likelihood that someone will experience guilt instead of shame in response to a negative event. Work environments may have a large impact on employee reactions to performance failure by influencing employees' cognitive appraisals of events, which, in turn, produce discrete emotional responses (e.g., Elfenbein 2007; Haidt 2003; James 1884; Pizarro \& Bloom 2003; Roseman 1991; Schachter \& Singer 1962). As Haidt (2003) pointed out, "changing the facts of the situation" can dramatically alter a person's emotional response to that situation (p. 197). Along a similar vein, we propose that the extent to which employees label an emotion as "guilt" more so than "shame" can be shaped by characteristics of the work environment.

We outline a theory of how employees' negative reactions to failure can be modified so that they are less debilitating (although not necessarily less negative). Drawing from past research in clinical, social, and organizational psychology, we first provide a general overview of the relationship and the established differences between guilt and shame. We then present the case for how promoting guilt over shame reactions in response to performance failures at work can be advantageous for both individual employees and organizations. We go on to describe the necessary antecedents for guilt: employees are likely to experience guilt if they feel they had control over a specific negative event that resulted in a negative outcome for others (in contrast, employees who experience a negative event as pervasive and causing negative outcomes for themselves are likely to experience shame). Given these preconditions, we identify a set of organizational characteristics — namely, autonomy, specificity of performance feedback, and outcome interdependence - that can increase the likelihood that employees will experience guilt without simultaneously increasing the likelihood that they will experience shame. We conclude by discussing the implications of these ideas and highlighting the importance of investigating discrete 
emotions at work. Finally, we address the ethical and practical limits of shaping employees' emotional experiences, especially forms of negative affect.

\section{Guilt and Shame}

Guilt and shame are common affective reactions to committing transgressions-either doing something one should not have done or, conversely, having not done something one should have done (Tangney 1991). In fact, guilt and shame share many similarities. Neither is considered a "basic" emotion (e.g., sadness, joy, disgust); rather, both belong to a smaller category of affective experience known as “self-conscious” emotions (e.g., Tangney \& Dearing 2002; Tracy \& Robins 2006). Self-conscious emotions entail self-evaluation, or a comparison of one's current state to some desired state (Tracy \& Robins 2006). More specifically, guilt and shame are negative self-conscious emotions_- "dysphoric experiences that involve a negative evaluation of the self or the self's behavior" (Tangney, 1990, p. 105).

Due to the similarities between guilt and shame, people who tend to experience one also tend to experience the other, as indicated by positive correlations in individual-difference measures of guilt- and shame-proneness ranging from .43 to .48 (Tangney, 1990). It is also not uncommon for an individual to feel both shame and guilt in response to the same event. For example, an individual transgressor may initially experience shame in response to a mistake he or she has made, but this response may eventually morph into a guilt response as the transgression is recalled and reinterpreted (Lewis, 1971). As Tangney (1990) explains, "one would expect shared variance reflecting the features shared by shame and guilt" (p. 105). Nevertheless, there is also "substantial, meaningful unique variance, reflecting the critical differences between shame and guilt" (Tangney 1990, p. 105).

Despite their similarities, guilt and shame are distinct emotional experiences with dramatically different consequences, especially in regard to social functioning (Baumeister, Stillwell, \& Heatherton 1994; Haidt 2003; Tangney \& Dearing 2002). People who are guilt-prone tend to be both empathic (George 1991; Leith \& Baumeister 1998; Tangney 1990; 1991) and averse to disappointing others (Horney 1937). Moreover, guilt-proneness is negatively related to Machiavellianism, or the tendency to manipulate others for personal gain (Wastell \& Booth 2003), and is negatively related to the desire for 
power and hedonism (Silfver, Helkama, Lonngvist \& Verkasalo 2008). Further, feelings of guilt motivate a person to confess, apologize, and atone for their past miscues, rather than deny culpability or displace blame onto others (Lewis 1971; Tangney \& Dearing 2002; Tangney et al. 1996). As a result of these prosocial qualities, feeling guilty has been shown to lead to higher levels of helping (Cunningham, Steinberg, \& Grev 1980; Freedman, Wallington, \& Bless 1967; Konecni 1972; Lindsey, Yun \& Hill 2007) — similar to levels of helping driven by positive mood, albeit with differing motivation (Cunningham, Steinberg, \& Grev 1980). Likewise, guilt has been associated with increased intentions to donate resources to those in need (Basil, Ridgway \& Basil 2008) and to cooperate in social bargaining games (de Hooge, Zeelenberg, \& Breugelmans 2007; Ketelaar \& Au 2003).

In contrast, the affective experience of shame correlates with negative social functioning. Shame can debilitate individuals by making them feel powerless and worthless. Evidence suggests that such demoralizing beliefs result in two primary maladaptive reactions. First, while guilt is associated with a desire to proactively repair a bad situation, shame is associated with an impulse to disappear or hide (Tangney et al. 1996). One consequence of this "desire to hide or escape from interpersonal situations" (Tangney 1991, p. 599) is that shame-prone individuals are more likely to avoid than confront a problem. Second, although feelings of shame and guilt were once both thought to repress hostility (e.g., Ausubel 1955), recent research has shown that shame (but not guilt) is associated with increased levels of aggression. For example shame-prone individuals tend to exhibit less adaptive responses to frustrating events, including expressions of resentment, suspiciousness, and blaming others (Tangney 1991). Although seemingly incompatible, these two shame responses_- hiding and lashing out — likely create a positive feedback loop of frustration and aggression. An ashamed individual lashes out in a "humiliated fury," and then "recognizes this humiliated fury as inappropriate or unjust" (Lewis 1987). This recognition may lead to further shame, which, in turn, leads to more hiding (Tangney 1992, p. 670). Leith and Baumeister (1998) provide a disheartening summary of the dysfunctional effects of shame: "the only resources that seem to minimize the subjective distress of shame are to ignore the problem, to deny one's responsibility, to avoid other people, or perhaps to lash out at one's accusers" (p. 4). 


\section{Guilt and Shame in the Workplace: Motivation and Performance in Response to Failure}

Guilt is more functional than shame, in general, but why should organizations, in particular, be interested in the distinction between these two emotions? Self-conscious emotions, such as guilt and shame, entail self-evaluation, or a comparison of one's current state to some desired state (Tracy \& Robins 2006). This quality of self-conscious emotions makes them particularly relevant to understanding motivation and performance within achievement and work domains, which regularly require individuals to assess their progress toward some goal or set of objectives (e.g., Seo, Feldman Barrett \& Bartunek 2004; Stipek 1995; Weiner 1985). Thus, guilt may provide specific advantages over shame in terms of employee motivation and performance.

We argue that organizations may benefit from the distinct proactive and prosocial qualities of guilt. Guilt promotes taking action while shame promotes avoiding action; relatedly, employees who are proactive rather than avoidant are likely to respond more effectively to performance failures. As for its prosocial qualities, guilt "stimulates attachment behavior such as in-group loyalty" (Baumeister et al. 1994, p. 250) and functions "to repair damage to a relationship arising from a transgression" (p. 257). In organizations, performance failures may qualify as "transgressions against the group" —whether the "group" is the organization, one's department, or one's closest colleagues. To the extent that employees believe a personal transgression harms their "in-group," they will likely experience guilt and attempt to rectify any harm done to fellow group members. Overall, then, while an employee may feel both guilt and shame in the face of failure, he or she should demonstrate higher levels of motivation and performance when feeling guilt rather than shame.

\section{Guilt's Influence on Emplovee Motivation and Performance}

Previous work on the influence of emotion on motivation and performance has highlighted positive affect as a determinant of task effort and motivational intensity (Seo, Feldman Barrett, \& Bartunek 2004). For example, George and Brief (1996) find that positive affect leads to increased expectancy (through self-efficacy) and utility (through optimism) (see also Lyubomirsky, King, \& Diener 2005). Analogous arguments by Wright and Staw (1999) use goal-setting theory to show how positive 
affect leads individuals to set higher goals that in turn lead to greater performance, and attribution models of motivation to show that individuals in a good mood are less likely to blame themselves for failures, attributing those failures instead to external causes that are less incapacitating. Wright and Staw (1999) further suggest that the link between positive affect and performance might be driven by interpersonal factors: because happy people are more attractive to others, they are more likely to receive positive peer evaluations, to be chosen as team members and leaders, and to receive help with tasks.

Some of the theoretical accounts that link positive affect to increased motivation and performance (Wright \& Staw 1999) may be useful as analogies for understanding the role of guilt in explaining the same employee outcomes. For example, like positive affect, guilt is associated with heightened confidence and self-efficacy (e.g., Covert, Tangney, Maddux, \& Heleno 2003; Tangney 1995), which should lead to judgments of greater expectancy and utility (in Vroom's [1964] model of motivation) as well as higher aspirations (in goal-setting theory). As mentioned earlier, experiences of guilt also tend not to elicit stable, global attributions of incompetence or worthlessness in response to failure-responses that can lead to incapacitating self-blame and impaired performance in the face of difficult obstacles (Tracy \& Robins 2006). Finally, guilt-prone individuals, like happy individuals, tend to be well-liked, and dispositional guilt has generally been associated with more favorable interpersonal outcomes (Tangney \& Dearing 2002). In the work domain, these interpersonal outcomes may include the same advantages provided by positive affect in terms of receiving help, opportunities, and positive peer ratings that in turn translate into improved performance.

Recent empirical research on individual differences in guilt-proneness further supports the link between guilt and increased levels of motivation and performance. In both a field study and a laboratory setting, Flynn and Schaumberg (2012) found that higher levels of guilt-proneness were associated with greater task effort (e.g., time spent working). In short, guilt-prone people worked harder than their less guilt-prone counterparts. The researchers explained their findings based on highly guilt-prone individuals' motivation to avoid disappointing others, which translates into greater concern with repairing past mistakes and avoiding future miscues. This preliminary empirical evidence, along with several 
theoretical arguments for how emotions can be translated into work motivation and performance, leads us to posit that feelings of guilt will have a positive impact on individual motivation and performance.

Proposition 1: Feelings of guilt following performance failure will be associated with increased employee motivation and performance.

\section{Shame's Influence on Employee Motivation and Performance}

Although guilt resulting from a performance failure will likely lead to increased employee motivation and performance, the case of shame is quite different. Guilt prompts individuals toward outward-focused action that addresses the source of the negative affect. However, shame triggers an inward focus (Lewis 1971) on the self that leads individuals to make global and stable attributions for their errors. Rather than focusing on a particular behavior and its consequent outcome ("I did a horrible thing"), an individual experiencing shame is more likely to focus on the self ("I did a horrible thing"). This general attribution to the self may lead an individual to disengage from difficult tasks, rather than putting in additional effort to meet a challenge. For example, he or she might think, "If that's just the way I am, no amount of effort can change that” (cf. Mueller \& Dweck 1988).

Such attributions can lead an individual to feel incompetent and inadequate (Tangney et al. 1992). Given a sense of low self-worth, shame-ridden individuals may begin to doubt whether they are capable of performing their assigned tasks. In motivational terms, such feelings of self-doubt may undermine their performance through decreased self-efficacy and expectancy (Covert, Tangney, Maddux, Heleno 2003; Vroom 1964). In behavioral terms, the pain of feeling incompetent may lead individuals experiencing shame to abandon tasks that have been performed incorrectly, without attempting to fix them, in an attempt to escape from the shame-inducing situation (Tangney et al. 1996). For example, the most commonly used shame-proneness scale asks respondents what they would do if they broke something at work and then hid it. Highly shame-prone individuals say they would be more likely to "think about 
quitting” (Tangney, Wagner \& Gramzow 1989), a clear indication of trying to hide from, rather than fix, a mistake.

The affective experience of shame is associated with feelings of frustration and aggression (Tangney et al. 1992; 1996), which can directly undermine individual work performance (McCollKennedy \& Anderson 2002; Pearce \& Porter 1996; Spector 1975). Such feelings can also lead to negative interpersonal outcomes. To ward off painful self-blame, shame-prone individuals tend to be more resentful, suspicious, and accusatory, all of which would make it difficult for individual employees experiencing shame to enlist help from their colleagues (Tangney, 1995). Highly shame-prone individuals tend to be more concerned with others' evaluations of them than with the consequences of their actions for others. For example, the shame-proneness scale mentioned above also asks what the respondent would do if a co-worker was blamed for his or her mistake. Highly shame-prone individuals say they would be more likely to "keep quiet and avoid the co-worker," an action that is not likely to win many friends.

Some empirical evidence supports a link between shame and decreased motivation and performance. In two samples of Dutch salespersons (Bagozzi, Verbeke \& Gavino 2003 and Verbeke \& Bagozzi 2002), shame was correlated with lower sales. In both cases, the researchers argued that this diminished performance resulted from a tendency to withdraw as a means of protecting the self rather than reaching out to make amends, establish connections, and utilize available resources. These preliminary findings corroborate our argument that shame-ridden employees will experience low selfefficacy and will be less likely to take action in order to repair a mistake. Thus, we put forth the following proposition - that feelings of shame will have a negative impact on individual motivation and performance in the aftermath of failure.

Proposition 2: Feelings of shame following performance failure will be associated with decreased employee motivation and performance. 


\section{The Antecedents of Guilt and Shame}

We propose that features of the work environment can foster more adaptive emotional responses to failure (i.e., guilt) over less adaptive emotional responses (i.e., shame). Although most research on the relative benefits of guilt over shame has focused on trait guilt- and shame-proneness, guilt (or shame) can also be elicited as a state response to an event with similar benefits (or costs; Kugler \& Jones 1992). In the current section we identify the general antecedents of guilt and shame states (i.e., the cognitive appraisals that lead an individual to experience guilt or shame in response to a given event). In the subsequent section, we will elucidate how each of these appraisals corresponds to a specific organizational feature in our model.

An individual's emotional response to an event is determined by how the individual makes sense of or appraises the event (Frijda 1986; James 1884; Lazarus 1991; Roseman 1991; Schachter \& Singer 1962). To identify the types of appraisals that engender guilt and shame, we draw from studies of guiltand shame-proneness (Tangney 1990; Tangney, Wagner, \& Gramzow 1989), research that has categorized situational antecedents to guilt and shame (Tangney 1992), and a cognitive appraisal theory that is especially useful for distinguishing between self-conscious emotions (like guilt and shame) (Manstead \& Tetlock 1989). Research on guilt- and shame-proneness, which relies on the Self-Conscious Affect and Attribution Inventory or, "SCAAI," and the more commonly used Test of Self-Conscious Affect or, "TOSCA," has categorized the types of appraisals that distinguish between guilt- and shameprone individuals (Tangney, Wagner, \& Gramzow 1989). In particular, these distinctions include a tendency to make internal, global, and stable attributions for a negative outcome (predictive of shame) or external, specific, and unstable attributions for a negative outcome (predictive of guilt; see also Tracy \& Robins 2006; Woien, Ernst, Patock-Peckham \& Nagoshi 2003). Tangney (1992) added an interpersonal component, suggesting that concerns with others' evaluations (i.e., how my behaviors affect the way other people think of me) "are almost exclusively the domain of shame" (p. 206). Finally, Manstead and Tetlock's (1989) cognitive appraisal theory attempted to distinguish between guilt and shame attributions. 
Specifically, Manstead and Tetlock suggest that, "[e]pisodes giving rise to shame...were appraised as less harmful to others than were guilt episodes" (p. 231).

Combining these lines of research, we identify three critical appraisals for distinguishing between guilt and shame: (1) Perceptions of control - guilt requires believing that one has control over a negative outcome, while shame can occur even if one believes s/he had no control over a negative outcome (Tangney 1990; Tangney, Wagney \& Gramzow 1989; Tracy \& Robins 2006; Woien et al., 2003); (2) Object specificity - the object of a guilt response tends to be highly specific (e.g., a particular behavior), whereas the object of a shame response tends to be a generalized or non-specific aspect of the self (e.g., Tangney 1990; Tangney, Wagney \& Gramzow 1989; Woien et al., 2003); (3) Negative outcomes for others - people tend to feel guilty when they commit a transgression that harms others or affects others' outcomes (an outward-focused attribution; e.g., Manstead \& Tetlock 1989), but they feel ashamed when they do something that affects others' evaluations or opinions of them (an inward-focused attribution; e.g., Tangney 1992).

\section{Perceptions of control}

As self-evaluative emotions, guilt and shame require feeling personally responsible for a negative event; that is, an individual must make a cognitive appraisal that something about the self — either a behavior or some aspect of the self—caused a negative outcome to occur (cf. Benedict 1946). However, one important factor for determining whether an individual will experience guilt is the individual's appraisal of control over that aspect of the self, and, consequently, one's control over the negative outcome (Tracy \& Robins 2006; Weiner 1985). For example, an employee who negotiates a bad deal may believe that he is both responsible for the outcome of the negotiation and that he could have done something to prevent the poor result; for instance, he could have prepared more beforehand. When people feel guilty for events such as these, they often recall the event by using active phrases, such as, "If only I...," or "I could have..." (Lindsay-Hartz, de Rivera, \& Mascolo 1995). Such attributions imply that the actor had some form of control over the event, and thus, a guilt response is predictable. 
This sense of control is not, however, necessary for a shame response. Individuals can also feel responsible for things they believe they cannot control. For example, the employee who negotiates a bad deal can still feel entirely responsible for the outcome of the negotiation while simultaneously feeling like there was nothing she could have done about it; she could feel that her poor performance results from a core aspect of her identity: that she is a terrible negotiator. When people feel ashamed (not guilty) about an event, they will typically recall it using phrases such as, “That's just the way I am...," or "I can't do anything right...” (Lindsay-Hartz, de Rivera, \& Mascolo 1995). Such attributions imply a lack of control over the negative outcome because some fixed aspect of the self caused the outcome to occur.

In fact, attributions of control for negative outcomes are malleable (Diener \& Dweck 1980; Langer 1975; Roseman, Spindel, \& Jose 1990). For example, the phenomenon known as "learned helplessness" (Seligman \& Maier 1967) refers to making attributions that negative events are external and out of one's control even when such events are in fact controllable (Mowrer 1960; Seligman 1975). However, the tendency to make such attributions can be altered through cognitive behavioral therapy (CBT), which involves challenging an individual's appraisal of negative events on this control dimension (e.g., Beck 1970). Mueller and Dweck (1988) have shown that attributions of control can also be altered through the type of performance feedback that is given and that such appraisals can have lingering consequences for future performance. For example, they found that attributing children's success in an initial task to a fixed aspect of the self (i.e., "You must be really smart") as opposed to a controllable aspect of the self (i.e., "You must have worked really hard") negatively affected children's motivation to persist in the face of failure.

Beyond manipulating attributions of controllable versus uncontrollable aspects of the self, other researchers have experimentally manipulated whether a particular event is perceived as controllable or uncontrollable (e.g., Cohen, Rothbart \& Phillips 1976; Sherrod et al. 1977; Wortman 1975). In a classic study by Langer and Saegert (1977), this was done through a commonplace change in participants' surroundings (i.e., whether they completed a task in a crowded or uncrowded grocery store, see also Sherrod 1974), and via a typical induction of perceived control in which participants either had or did not 
have access to relevant information. Participants in this study felt as if they had less control over their environment when they were surrounded by a large number of people; however, they recaptured some sense of control when they were provided with information about possible reactions they might have to being in a crowded environment. In sum, the attribution of control—a key component of guilt, but not shame - is malleable and subject to the influence of one's environment, which suggests that organizations can use principles of job design to influence these appraisals ${ }^{1}$.

\section{Object Specificity}

Another important difference between guilt and shame is the specificity of the object thought to have caused the negative outcome (Tangney 1991): while the object of a guilt reaction is highly distinct, the object of a shame reaction is more global and far-reaching. People experience guilt when they attribute a negative event to a specific behavior; the aversive experience does not generalize to other unrelated domains or generate far-reaching self-evaluations (Lewis 1971; Smith, Webster, Parrott \& Eyre 2002; Tracy \& Robins 2006). To return to our earlier example of the employee who negotiated a bad deal, that employee would feel guilty for his poor performance if he were to appraise his error as a situation- or behavior-specific failure (e.g., "I have trouble regulating my emotions when I'm tired. I should have gotten more rest.”). Because he attributes his experience to a particular situation, his future performances under slightly different circumstances would likely not be negatively affected. This experience and appraisal stands in contrast to shame, where the cause of an aversive outcome is attributed more globally to the self, which is why shame can often lead to feelings of self-hatred, isolation, and worthlessness (Tracy \& Robins 2006). An employee who appraises the negotiation experience as more generally representative of his identity or aptitude ("I always get anxious in confrontational situations.") is not only more likely to feel ashamed but is also more likely to avoid negotiating in the future.

Like attributions of perceived control, attributions of specificity are not fixed. For example, CBT (Beck, 1970) can alter the generality of attributions that depressed individuals make following a negative event; the goal in such therapy is to move individuals from the notion that "I mess everything up" to the appraisal that "this is an isolated incident." Experimental psychologists have also manipulated global 
versus specific attributions in the lab. For example, Keltner, Locke, and Audrain (1993) had participants who performed poorly on a midterm exam reflect on how they were feeling either "right now in response to the exam" or "right now in response to things in general."

The flexibility of specificity appraisals has also been demonstrated in research on construal (e.g., Trope 1989; Trope \& Liberman 2003). Whereas high-level construals focus on how important or desirable an outcome is - the "why" of an event—low-level construals focus on feasibility and planning - the "how" of an event. In the context of guilt and shame reactions, global attributions (e.g., attributions to the self) are considered high-level construals, while specific attributions (e.g., attributions to a particular situation or behavior) are considered low-level (Nussbaum, Trope, \& Liberman 2003). An individual's construal of a performance failure can be altered by having him focus on the details of how the event unfolded instead of its broader meaning. When individuals are encouraged to focus on specific, low-level construals for negative events, they evince better problem-solving, self-regulation, and performance (Pham \& Taylor 1999; Taylor \& Schneider 1989; Watkins \& Teasdale 2001).

Further, Williams and Bargh (2008) have demonstrated that construal level may be influenced by an individual's surroundings, including environmental cues of spatial distance or proximity. Participants who were primed with physical distance in these studies (by locating two coordinates that were far apart, as opposed to close together, on a Cartesian plane) exhibited higher-level construals of events they were presented with later in the study than did participants primed with physical closeness. This malleable nature of specificity attributions suggests that targeted job design could shift an individual's focus from the global, high-level implications of a performance failure to the more specific, low-level causes.

\section{Other-oriented outcomes versus self-oriented distress}

Shame and guilt are both social emotions. However, the social experiences that elicit guilt over shame are very different. Guilt arises when an individual appraises that his actions caused harm to someone else, whereas shame arises when an individual appraises that his actions affected others' evaluations of himself. Given the opposing focal point of these appraisals - outward-looking for guilt, inward-looking for shame — shame tends to be more associated with the public nature of a failure than 
does guilt (see Smith, Webster, Parrott, \& Eyre 2002). We can thus differentiate guilt from shame on a third dimension: the social outcomes of a negative event. Returning once again to our earlier example, if the unsuccessful negotiator were to construe her performance as costing her co-workers time or moneyan ostensible "offense against the group" — she would likely experience guilt (Ausubel 1955; Zeelenberg $\&$ Breugelmans 2008). However, if she were to focus instead on what her colleagues must be thinking of her for her poor negotiation skills and the possibility that they might reject her-a potential threat to the “social self” (Dickerson, Gruenewald, \& Kemeny 2004)—she would likely experience shame.

Other- and self-oriented attributions are unique from attributions of control and attributions of specificity because they are not mutually exclusive. Although it is practically impossible to feel both in control and out of control at the same time, it is possible to feel that one has both harmed the group and is being negatively evaluated by the group simultaneously. For these reasons, an individual who negotiates a bad deal may feel guilty for producing a poor outcome for her colleagues and ashamed over what they must think of her negotiating skills. Although previous research has indicated this potential for individuals to experience both shame and guilt in response to an event (Lewis, 1971), it is unclear whether and how the presence of shame might mitigate the positive effects of guilt. We surmise that provided an individual's attributions of control and specificity are aligned and an individual is relatively more focused on the effect of one's outcomes on the group than one's standing in the group, a constructive guilt response will predominate.

As with control and specificity, this "social" appraisal dimension can be influenced by contextual factors. The more that certain aspects of a situation make an individual aware of and focused on the effect of his actions on others, the more likely it is that this individual will experience guilt (cf. Schaumberg \& Flynn 2012). For instance, research on charitable fundraising has demonstrated that inducing guilt through vivid portrayals of others' suffering, which elicits "other-oriented empathy" (Tangney, Stuewig, \& Mashek 2007), can effectively increase donation intentions (Hibbert, Smith, Davies, \& Ireland 2007). Indeed, recognizing the impact that one's actions can have on others is considered an important part of the development of individual moral judgment: for example, parents might point out to a child, "Look, your 
sister is crying," in order to draw a child's attention to the harm he has caused others (e.g., Lagattuta \& Thompson 2007).

Conversely, contextual factors can elicit shame if they are framed so that individuals attend to others' opinions of them and feel more "exposed" to others' negative evaluations. For example, parents sometimes call attention to a child's bad behavior by chiding, "You should be ashamed of yourself." This expression gives the child direction about how she should feel about herself, rather than how to appraise the effect of her actions or behavior on others (e.g., Kochanska \& Thompson 1997). Competition can also induce shame responses: viewing any performance failure as a competitive defeat can further heighten the experience of shame so that a defeat affects an individual's standing in the group (Lewis 1971). In sum, one's focus on self versus other also appears to be malleable, and can therefore be influenced by principles of job design that draw an individual's attention to how her actions affect group outcomes more so than her standing among group members.

\section{The Role of the Work Environment in Promoting Guilt Responses to Failure}

We have outlined the advantages of a guilt response over a shame response to failure in the workplace, as well as the ways in which an individual must appraise a situation in order to experience guilt and not shame. In this section, we explain how organizations can attempt to elicit a guilt response to failure from employees. One might assume that organizations could potentially capitalize on the value of guilt over shame reactions to failure by simply hiring individuals who are more likely to make attributions that lead to feelings of guilt as opposed to shame - that is, individuals who have a high level of guiltproneness and a low level of shame-proneness (Tangney 1990). However, individual differences are not the only determinant of an individual's emotional reaction to failure. Contextual cues from the environment are also important in determining such reactions.

To be clear, we are defining the "environment" as a set of external cues characteristic of an employee's work setting from which the employee draws information that can be used to interpret each new situation. For example, when faced with a performance failure, an employee may wonder, "Does this mean I'm bad at my job or that I should have paid more attention during training?" To interpret the 
meaning of this event, the focal employee may look to social cues from the environment. For example, he or she may surmise, "My co-workers seemed peeved when I left in the middle of the training session." According to Salancik and Pfeffer (1978), "The social environment provides cues which individuals use to construct and interpret events. It also provides information about what a person's attitudes and opinions should be" (p. 225). The employee may also look to structural cues (Blau 1960). For example, he or she may think, "This error report form asks specifically about whether I completed the entire training." We propose that altering the variety of social and structural environmental cues that employees use to make attributions for events may alter an employee's emotional appraisal following a failure.

There is clear evidence for the effect of the environment on individuals' cognitions and behaviors in the workplace. Research suggests that employees' attitudes and behaviors tend to be consistent with organizational norms and values (Davis-Blake \& Pfeffer 1989), and that organizations can actively shape employees' attitudes and behaviors via organizational culture (Wilkins \& Ouchi 1983). Cultural norms can influence how individual employees make sense of problems they encounter (Harris, 1994), and how they should interpret others' behavior (Arkin \& Duval 1975; McArthur \& Post, 1977).

Of particular relevance to our model, there is prior evidence for the effect of the environment on an individual's attributions, or cognitive appraisals, for failure specifically. Bitner (1990) explored the effects of environmental cues on customers' attributions for a service failure, particularly their attributions of control and stability. Bitner (1990) found that when customers encountered a service failure, the physical appearance of the organization affected the attributions they made for the failure. When the organization appeared organized and professional, the customers were less likely to attribute the service failure to stable factors - instead, assuming the mistake was limited to a specific, temporary situation. They were also less likely to attribute responsibility for the failure to the firm-instead, determining that the firm must not have control over the situation.

In sum, research suggests that environmental cues can alter how individuals react to negative events in the workplace. Specifically, the structure of one's work environment can shape employees' emotional reactions to performance failure (see also Sheperd, Patzelt \& Wolfe 2011). In this section, we 
identify features of the work environment that can alter employees' attributions for a failure in ways that elicit guilt. Our complete model (summarized in Figure 1) indicates that the appraisal process involves first identifying an event as a performance failure ${ }^{2}$. Once the event is encoded as a failure, features of the environment will determine how an individual answers the following three questions, which, in turn, determine whether she experiences guilt or shame: (1) Could I have done something different to prevent the negative event from occurring? (2) Am I focused on a specific maladaptive behavior, or am I focused on a global attribute of myself? (3) Did my failure affect the group, or my standing in the group? If a person does not feel she could have controlled the event, cannot identify a specific behavior as having triggered the negative event, or views the event as a personal failure that has no effect on others, the event will not produce guilt. Alternatively, if the person believes she did not have control over the event because of some stable or global aspect of the self, and if she focuses on others' negative opinions of her rather than the effect of an event on others' outcomes, a person will likely experience a shame reaction and may in turn feel hopeless: "I give up; I am terrible at this job."

In this section we describe three features of the work environment that together are likely to promote a guilt response over a shame response to failure. We focus on these three features because of their relationship to the three attributions that give rise to guilt, which we reviewed earlier. Specifically, guilt responses should be more prevalent in organizations that (1) grant their members autonomy, (2) engage with failures and try to understand the specific behaviors that caused them (i.e., by giving specific performance feedback), and (3) emphasize communal goals over individual goals. As depicted in Figure 1, when employees experience performance failure, these three features of the work environment can intervene in the emotion regulation process by affecting their appraisal of the event - eliciting either a guilt reaction that should positively affect future task motivation and performance, or a shame reaction that should negatively affect motivation and performance. While each of these three organizational features has been studied independently, in an organizational setting these features likely do not operate in isolation, but coexist and interact with one another. We are particularly interested in how the combination of all three features may impact employees' discrete emotional responses to failure. 


\section{Autonomy}

Hackman and Oldham (1976) defined autonomy as "the degree to which the job provides substantial freedom, independence, and discretion to the individual in scheduling the work and in determining the procedures to be used in carrying it out" (p. 258). To clarify the concept, Barrick and Mount (1993) use the example of an assembly line worker with a highly structured and supervised routine (low autonomy) and a salesperson who sets his or her own schedule and is monitored remotely (high autonomy) (p. 112). High-autonomy jobs offer employees some instruction on what they need to accomplish and then allow employees the freedom to determine how they will best meet that goal (Langred \& Moye 2004). Employees with high levels of autonomy have more flexibility in determining their own work schedules and have some level of decision-making power; they do not need to seek approval from a supervisor for every decision they make (Hackman 1980).

Autonomy clearly relates to the first cognitive appraisal that accounts for whether someone will feel guilt in the face of failure: perceived control. As Davis (1977) explains, autonomy is "the job characteristic that gives employees some control over their own affairs" (p. 239). We argue that a sense of autonomy is a necessary precondition for an employee to experience guilt following a performance failure. As discussed in the previous section, an employee can feel responsible for an event and still feel that there was nothing he could have done to prevent it — that he had no control over the negative outcome. Without this perception of control, the employee will not feel guilty for the failure. For example, an employee may be responsible for managing a particular client, but have no authorization to negotiate with the client over fees. If the employee were to lose the client as a result of this issue, the employee would easily be able to attribute such a loss to the structural circumstances preventing the employee from negotiating a more agreeable contract; in his appraisal of the situation, he might think, "My hands were tied" and therefore feel no guilt. However, because shame does not require this attribution of control, the negative affect experienced by this employee could still take the form of shame. Instead of thinking, "My hands were tied," the employee could think, "My employer does not trust my 
decision making, which is why I was not allowed to negotiate the contract." Thus, a shame reaction remains a possibility when employees lack autonomy, but a guilt reaction should not occur.

Conversely, employees with high levels of autonomy are more likely to attribute their mistakes to their own decisions ("If only I. ..") than to some external cause ("My employer...”). When employees believe they could have prevented a negative event from occurring, they are more likely to experience guilt (Lindsay-Hartz, de Rivera, \& Mascolo 1995). Noting this, we propose that autonomy is necessary for producing an experience of guilt following a performance failure. At the same time, attributions of control do not eliminate the possibility of experiencing shame. For example, an employee might think, "I had the autonomy to negotiate the contract and I failed because I am generally a bad employee.” Thus, even with high autonomy, an individual may experience shame following a performance failure.

However, because this attribution of control is not necessary to produce a shame response, autonomy and shame should essentially be orthogonal. This means that greater autonomy should increase the likelihood that an employee will experience a guilt response following failure without necessarily increasing the likelihood of a shame response.

Proposition 3: Greater autonomy will lead to cognitive appraisals of control over negative events that transpire at work, which will increase guilt without necessarily increasing shame following a performance failure.

\section{Specificity of Performance Feedback}

Managers tend to be leery of providing negative performance feedback to employees (Fisher 1979; Ilgen \& Knowlton 1980; Larson 1986; 1989). Instead, common practice may be to "sweep it under the rug." At the same time, individual employees are motivated to use feedback-seeking strategies that minimize the amount of negative feedback they receive (Ashford 1986). However, this habit prevents employees from acknowledging their performance failures and attempting to correct their mistakes (Larson 1989). By ignoring or failing to recognize mistakes, organizations may miss opportunities for 
improvement in production or the delivery of services. We argue that employers should engage in giving negative feedback, but they should offer it in a manner that induces guilt, not shame. Negative feedback is not bad, per se; rather, individuals' emotional reactions to this feedback can be more or less adaptive. Guilt, as we have argued, may be especially adaptive.

Performance feedback varies in terms of specificity, from general descriptions to precise details. General feedback can take the form of an assessment of how employees compare to peers using coarse categorizations; specific feedback can take the form of a task-specific response such as "When you do , you should do it more like ___." In their meta-analysis of the performance feedback literature, Kluger and DeNisi (1996) concluded that feedback specificity was an important moderator in determining the effectiveness of feedback interventions for improving performance. When negative feedback was highly task-specific, performance improved following the feedback intervention; when negative feedback was more general, performance was subsequently impaired due to a perceived threat to self-esteem. Similarly, in their study of performance feedback given to students, Butler and Nisan (1986) found that those students who received task-specific feedback were more intrinsically motivated when they resumed the task at hand than were students who received feedback about how their performance ranked in comparison to their peers and students who received no feedback at all.

In general, people will experience negative (not positive) affect in response to negative performance feedback whether it is specific or not (Illies \& Judge 2005), and it is unlikely that feedback specificity will lessen the target's distress. However, based on our review of the situational features that elicit guilt over shame, we posit that feedback specificity changes the way employees appraise negative feedback situations, and, thus, changes the form of the negative emotion they experience. Because general feedback — “We haven't been happy with your performance"—appears to reflect on the self, generally speaking, rather than a specific behavior, it prompts cognitive appraisals that lead to shame. Conversely, negative feedback that focuses on particular actions related to a task or job role_- "We believe these specific behaviors are problematic because"-reflects a distinct miscue and not a global, stable attribute of the self. This more fine-grained, detailed feedback should evoke feelings of guilt. In 
sum, highly specific negative performance feedback engenders a more adaptive affective response (guilt) over a less adaptive response (shame).

Proposition 4: Specific feedback following a performance failure will lead employees to attribute shortcomings to specific behaviors rather than to global attributions of the self; the attribution to behavior is necessary for producing a guilt response instead of a shame response following a performance failure.

\section{Outcome Interdependence}

We suggest that a guilt response is more likely to follow a performance failure in situations that involve higher level of outcome interdependence. Wageman (1995) defines outcome interdependence as "the degree to which significant outcomes an individual receives depend on the performance of others" (p. 147). For our purposes, it may be useful to think of outcome interdependence as the degree to which significant outcomes one's coworkers receive depend on one's own performance. According to past research (e.g., Tangney \& Dearing, 2002), experiences of guilt relate to outward-focused rather than inward-focused appraisals: that is, employees experience guilt when they perceive that their actions have done harm to others, while they experience shame when they perceive that their actions have harmed others' opinions or evaluations of themselves (Tangney 1992). Although it is foreseeable that an employee will be concerned with others' evaluations of him or her following a mistake, an outward focus that directs the individual toward what the mistake means for the group's outcomes may steer their emotional reaction away from shame and toward guilt.

Outcome interdependence can be established through various means, including the structure of employee reward systems (emphasizing collective-oriented over self-oriented incentives), recognition for group instead of individual accomplishments, or an emphasis on group objectives rather than personal objectives. The key to establishing outcome interdependence is the set of environmental cues that indicate whether an individual's performance is valued for its effect on others or its indication of one's 
standing in the group. Outcome interdependence reinforces communal values and emphasizes the effect of individual performance on the group (Wageman, 1995). Conversely, outcome independence emphasizes individual performance and encourages comparisons and competition between individual employees. Independent reward systems highlight an individual's standing within the group.

Work environments that emphasize outcome interdependence may elicit different affective reactions to failure relative to those that emphasize outcome independence. In a setting that emphasizes outcome interdependence, employees who fail to meet performance expectations know that they are adversely affecting both their own outcomes and those of their coworkers. Although an employee's mistake may never be made public to the group, he or she may be reminded of the group's shared fate by various environmental cues (e.g., group photos on the wall or a prominent organizational mission statement). An employee's failure in such a system is considered a loss to the group, which would likely elicit feelings of guilt (Baumeister et al. 1994). As a result, employees in interdependent outcome systems should feel a stronger sense of obligation to correct or make up for their failings and to repair the harm they have caused (e.g., Tangney et al. 1996), even if it means working outside the normal schedule or on tasks that are not explicitly assigned to them (Barker 1993).

Conversely, employees that struggle in outcome independent systems may feel more ashamed than guilty as they compare their failings with the performance of other individuals in the group (e.g., Lewis 1971). Emphasizing individual excellence over communal goals can take extreme forms: to use a notorious example, the corporate culture at Enron zealously rewarded and punished individual performance through a system colloquially referred to within the company as "rank and yank," where "stars" were regularly promoted and poached between departments, often to the detriment of the organization as a whole (McLean \& Elkind 2003). In such a competitive system that emphasizes individual performance above all else, poor performers have no reason to feel guilty — the effect of their performance on the group is irrelevant. However, such an emphasis on competition and individual standing would likely induce shame for those who do not measure up (Lewis 1971). 
Proposition 5: Greater outcome interdependence will lead to cognitive appraisals of how one has harmed others (rather than how others view the self) following a performance failure; this outward-focused appraisal will increase guilt without increasing shame.

Thus far, we have described the separate contributions of each feature of our model. However, it is important to note that our model predicts a constructive guilt response to failure only when all three levers are properly “adjusted." That is, autonomy must be high, performance feedback must be specific, and an employee's performance must have an effect on others. If any one of these elements is missing in a failure situation, it can decrease the likelihood of a guilt response. For example, an employee who is given specific feedback about a poor decision she made that negatively affected group outcomes, but was not given the autonomy to have made a different decision by her manager, may feel frustrated, but she is unlikely to experience guilt (the decision was out of her control). Similarly, a salesman with complete discretion over how he pitches a product who learns that a specific element of his pitch isn't working may be disappointed with his performance and feel compelled to make a change, but he is unlikely to experience guilt if his sales outcomes have no impact on anyone but himself. Such interdependence among these three elements is a key feature of the model. Although each element (e.g., high autonomy) may be associated with its own individual positive employee outcomes, it is the unique combination of these three features together that will make guilt a likely response to failure.

\section{Discussion}

Affective responses to performance failures represent an important topic of inquiry for researchers in organizational behavior given that poor service, technical errors, and tardiness are common experiences in most workplaces. The model presented here outlines some ways in which organizations can structure their environments so that the inevitable negative affective response employees have to these kinds of failures is less harmful — and potentially beneficial — to both the employee and the organization. Specifically, we have described the antecedents and consequences associated with guilt, a more adaptive response to failure, and contrasted them with the antecedents and consequences associated 
with shame, a less adaptive response. We have proposed that organizations should provide their employees with group goals, afford them autonomy in determining how to reach those goals, and provide specific feedback to let them know how they are doing. When an employee makes a mistake in such an environment, which employees inevitably will do, the emotional effects are likely to be mitigated and less damaging in terms of performance.

\section{Theoretical and Practical Contributions}

Many of our recommendations, such as increasing autonomy and giving specific feedback, are already considered to be good organizational practices. However, the assumption behind many of these prior recommendations is that such practices are associated with higher levels of positive affect felt by individual employees. For example, according to Hackman and Oldham, desirable job characteristics such as autonomy and specific feedback create "a positive self-generated affective 'kick" for individual workers (p. 60). The positive affect generated by these job characteristics has, in turn, been linked to a number of positive organizational consequences, such as organizational commitment and job satisfaction (Isen \& Baron 1991; Weiss \& Cropanzano 1996), which perpetuates a belief that these characteristics are desirable largely because they make employees feel good.

A major contribution of the current model is to propose that these job characteristics will not always make people feel good. Employees will feel bad when they encounter failure, even when they have high autonomy, specific feedback, and interdependent outcomes. Yet, as we have argued, some forms of feeling bad are better than others. We have identified a subset of desirable job characteristics that can shape employees' negative affective reactions - that is, their likelihood of exhibiting a more adaptive (guilt) or a less adaptive (shame) response to failure. This subset of features does not include all desirable job characteristics that are often linked to positive affect. For example, task variety is thought to produce positive affective experiences, (e.g., more stimulating work experiences and more positive affect toward one's career; Campion, Cheraskin, \& Stevens, 1994). However, based on our review of the antecedents of guilt versus shame reactions, which include control, specificity, and other-oriented outcomes, task variety, although desirable for other reasons, would not likely affect an employee's 
experience of guilt or shame following failure. Thus, our recommendations are unique in focusing on a particular subset of job characteristics that are relevant to guilt and shame, and in suggesting that these job characteristics need not make employees feel good in order to be good organizational practices.

Our model also highlights the role of formal features of the work environment in the regulation of employee emotions. Most research on guilt and shame examines either specific features of the transgression or the types of reparative behaviors that follow the transgression (e.g., atoning versus hiding). In contrast, our examination of these two discrete emotions emphasizes the malleability of emotional responses by outlining the contextual factors that may cause an individual to experience either guilt or shame. Drawing on emotion attribution theories, we propose that specific features of an organizational environment affect an individual's encoding of a personal failure, and, consequently, the extent to which the individual feels guilty or ashamed for that failure. This consideration of the role of the organizational environment in emotion regulation, particularly as it pertains to guilt and shame responses, has not been explored; thus, our model opens up new possibilities for organizations, which can actively promote more adaptive responses to failure by establishing reward structures and feedback mechanisms that help regulate employees' emotional reactions to failure.

Another contribution of our model is the clear case it makes for the importance of studying discrete emotions and isolating their distinct dynamics in the workplace. Past research on emotions in organizations generally focuses on the broad categories of negative and positive affect, in the process lumping together discrete emotions that have similar valence but different antecedents and consequences. This often means that shame and guilt are lumped together in a single construct of negatively-valenced emotions and not considered separately. Because we are interested in predicting how individuals react to specific objects and events, a focus on discrete emotions rather than broad categories of affective experience enables us to suggest more tailored approaches to mitigating harmful responses. Simply knowing that an employee feels badly upon hearing negative feedback cannot predict the impact that feedback will have on the employee's subsequent behavior and performance—one needs to know precisely whether the employee feels guilt or shame, for example, in order to predict their behavior. Our 
model demonstrates how researchers can draw on general frameworks of emotion in organizations (e.g., Elfenbein 2007) to make behavioral predictions for specific discrete emotions.

Finally, in addition to making a theoretical contribution, our model offers clear practical suggestions that can be easily implemented by managers in organizations. Previous research has asserted that negative emotions are counterproductive motivational tools (e.g., Edwards 1992; Luthans \& Kreitner 1985). Yet, performance failures are inevitable, and it is unreasonable to suggest that we could —or even that we should - eradicate negative affect entirely, particularly in the face of significant failures. Rather, our model can educate employers about how to channel negative affect in more productive ways, for example by equipping employees with a sense of control, useful feedback, and a communal spirit that will motivate them to rectify a bad situation. To this end, employers can emphasize features of the work environment, namely autonomy, specific performance feedback, and outcome interdependence, that will engender feelings of guilt rather than shame.

\section{Limitations and Future Research Directions}

\section{Individual Differences Related to the Model}

Guilt and shame may be related to several variables that were not incorporated into our model but are nonetheless relevant to organizations. For example, cultural values, such as collectivism and individualism, have been found to moderate (Bagozzi, Verbeke, \& Gavino 2003) and alter (Stipek 1998; Wallbott \& Scherer 1995) individuals' experiences of self-conscious emotions, such as shame, guilt, and embarrassment. Individuals in collectivistic cultures tend to be more aware of others' perspectives (Heine, Takemoto, Moskalenko, Lasaleta \& Henrich 2008) and the extent to which their behaviors affect other people (Bohns et al. 2011). Thus, their appraisals of events may be less affected by environmental interventions designed to draw attention to how their actions affect others. For these reasons, the same levers (e.g., increasing outcome interdependence) that may provoke guilt responses in, say, an American organization, may not elicit these responses to the same degree when applied to a Chinese organization. Further, individual differences in the propensity towards collectivism or individualism (e.g., Moorman \& 
Blakely 1995) may lead individual employees to react differently to changes in these organizational features.

Along a similar vein, individual differences might moderate the predicted relationships put forth here. As a personality variable, conscientiousness may be positively associated with the trait of guiltproneness, and negatively associated with shame-proneness. Conscientiousness correlates with a strong sense of personal responsibility (Smith 1967; Wiggins, Blackburn \& Hackman 1969) and selflessness (Moon 2001). Evidence also suggests that the link between conscientiousness and work performance is mediated through many of the same motivational factors that we have argued drive the link between guilt and performance in response to failure (Gellatly 1996). For example, highly conscientious individuals set high performance goals (Barrick, Mount, \& Strauss 1993; Barrick \& Mount 1993; Gellatly 1996), and demonstrate high performance expectancy (Gellatly 1996; Martocchio \& Judge 1997), which we have argued is likely to play a role in the link between guilt and work performance. The overlap between qualities associated with conscientiousness and qualities associated with guilt suggests that highly conscientious individuals may be particularly sensitive to antecedents and experiences of guilt and less vulnerable to cognitive appraisals associated with shame. Despite this potential overlap between conscientiousness and guilt, it is worth noting that Flynn and Schaumberg (2012) continued to find associations between individual differences in guilt-proneness, motivation, and commitment even when controlling for conscientiousness, suggesting that guilt should have an effect on employee outcomes above and beyond those of conscientiousness.

Finally, as mentioned earlier, guilt and shame have also been measured as individual-difference variables (Tangney 1990). Such individual differences in one's proneness to experiencing guilt or shame may interact with various features of our model. For example, both greater guilt-proneness and greater shame-proneness may lower the threshold at which an individual considers a negative outcome to constitute a performance failure. As a result of increased vigilance for potential shame- or guilt-inducing events in the environment, an individual who is highly guilt-prone may experience guilt for even the smallest transgression, while a person who is highly shame-prone may feel ashamed for an insignificant 
personal flaw or gaffe. Thus, individual differences in guilt- and shame-proneness may help determine whether our predictions apply more to particular individuals. Individual differences in guilt-proneness or shame- proneness may also affect individuals' perceptions of the factors in our model across multiple environments. For example, guilt-proneness may be consistently associated with greater perceptions of outcome interdependence in any work environment (viewing any work outcome as a group triumph or failure), while shame-proneness may have the inverse relationship (viewing any work outcome as a personal victory or defeat). As a result, the effect of structural features in the environment may have less influence on individuals who are already highly guilt-prone or shame-prone - that is, the effect of individual differences may outweigh the effect of the situation for individuals who fall especially high on the guilt- or shame-proneness spectrum (cf., Barrick \& Mount 1993).

\section{Ethical Concerns and the Hidden Complexities of Guilt and Shame}

It is worth noting some cautions and ethical concerns about using any negative emotion as a motivational tool. Although guilt may be less destructive than shame, extreme levels of guilt can lead to psychological distress, as can an extreme experience of any negative emotion (e.g., O'Connor, Berry \& Weiss 1999). Thus, while the experience of guilt may be beneficial in moderate amounts, too much guilt can become maladaptive. Moreover, organizations may risk a backlash if individuals feel that people in the workplace are intentionally manipulating them by appealing to their guilty consciences, or "guilttripping." In cases of perceived manipulation, employees may even perform worse on their assigned tasks (Brockner, Davy, \& Carter 1986). To avoid these negative consequences, we suggest that organizational leaders focus not on inducing guilt per se, but on implementing the constructive organizational practices (autonomy, specific feedback, and outcome interdependence) we have recommended to create an environment in which employees are likely to experience more adaptive emotional responses to failure. In short, although we have argued that individual experiences of guilt would be less likely to decrease morale than would shame, we do not endorse blatant and extreme attempts to induce feelings of guilt.

Moreover, we have presented a stark distinction between guilt and shame for illustrative purposes, but this distinction does not fully capture all the nuances of these two emotions. There are 
circumstances in which shame can sometimes be the more adaptive response, just as there are situations in which guilt can be debilitating. For example, it may be appropriate for employees to feel shame for violations of ethical transgressions such as stealing. In such a case, feeling shame regarding the perceived inconsistency between what someone wants to be (e.g., a "good person") and what their actions seem to say about them (stealing is inconsistent with being a "good person") forces an individual to look inward at his motives and core qualities in ways that can help instigate change. Shame and the anticipation of shame have also been shown to serve a self-regulatory function; in the example of stealing, an individual might think, "I won't steal because the shame would be too painful" (Izard 1977). Shame may also perform a group cohesion function by aligning group members' opinions about what constitutes appropriate behavior. Conversely, there are situations in which guilt can be debilitative rather than productive. For example, highly guilt-prone individuals with a strong sense of autonomy may overextend those feelings of control and consequently feel responsible for events that are, in fact, beyond their control. "Survivor's guilt" constitutes one example of such maladaptive guilt: many employees experience this emotion after seeing their co-workers get laid off (e.g., Brockner, et al 1986; Chodoff, Friedman, \& Hamburg 1964) even though they had no control over the layoff decision. In short, there are some circumstances when organizations would want to alleviate employees' guilt or even allow for experiences of shame.

\section{$\underline{\text { Conclusion }}$}

We have outlined a model for how organizations can shape employees' affective responses to past failure in order to produce more positive results in the future. Highlighting the distinction between the adaptive nature of guilt and the less adaptive nature of shame within social settings, we assert that this same distinction is important within the workplace. Further, we suggest that organizations can play an instrumental role in influencing employees' discrete emotional reactions to the benefit of both employees and the organization. The notion that any form of negative affect can be adaptive may seem counterintuitive to the casual reader who is more used to hearing that happy workers are productive workers. However, when we account for the unique properties of guilt, we recognize its motivational force in prompting employees to take corrective action following past mistakes or in advance of future 
shortcomings, while shame incites more detrimental effects. 


\section{Footnotes}

${ }^{1}$ The literature on self-enhancement suggests that attributing failure to some controllable aspect of the self is threatening to one's ego and would consequently be avoided at all costs. In support of this argument, Miller (1976) and Riess and Taylor (1984), among others (see Blaine and Crocker 1993), have found that individuals are less likely to take personal responsibility for failures than successes. This implies that people may be inclined to attribute their failures to external events, thereby avoiding the uncomfortable experience of guilt altogether. However, other research suggests this is not the case. For example, using an experience sampling method, Baumeister and Reis (1995) found that participants who were randomly signaled to complete a questionnaire over the course of a week reported feeling at least mildly guilty $12.7 \%$ of the time - an emotional experience as common as anxiety. Further, guilt was frequently associated with performance failures that were directly attributable to the self (e.g., procrastinating). Thus, it appears that the motive for self-enhancement may not preclude individuals from taking responsibility and experiencing guilt for their mistakes, particularly when they believe that they had some control over that negative event. For a more complete perspective on how the self-motives literature, which suggests that individuals are more likely to deflect personal responsibility for failure, may be reconciled with the literature on self-conscious emotion, which requires that an individual accept personal responsibility for failure, see Leary (2007).

${ }^{2}$ Note that in order for our model to apply, an event must be significant enough to be judged a performance failure by the individual. Some mistakes are simply not impactful enough to warrant a notable affective response (e.g., printing the wrong document may waste paper, but it is not significant enough to be a considered a performance failure). However, there may be individual differences in the threshold at which an individual will consider an event a performance failure, which we describe in greater detail in the discussion. 


\section{References}

Arkin, R. M. \& Duval, S. 1975. Focus of attention and causal attributions of actors observers. J. Experiment. Soc. Psych. 11 427-438.

Ashford, S. J. 1986. Feedback-seeking in individual adaptation: A resource perspective. Acad. Management J. 29 465-487.

Ausubel, D. P. 1955. Relationships between shame and guilt in the Socializing process. Psych. Rev. 62 378-390.

Bagozzi, R. P., Verbeke, W. \& Gavino, J. C. 2003. Culture moderates the self-regulation of shame and its effects on performance: The case of salespersons in the Netherlands and the Philippines. J. Appl. Psych. 88 219-233.

Barker, J.R. 1993. Tightening the iron cage: Concertive control in self-managing teams. Admin. Sci. Quart. 38 408-437.

Barrick, M. R. \& Mount, M. K. 1993. Autonomy as a moderator of the relationships between the Big Five personality dimensions and job performance. J. Appl. Psych. 78 111-118.

Barrick, M. R., Mount, M. K., \& Strauss, J. P. 1993. Conscientiousness and performance of sales representatives: Test of the mediating effects of goal setting. J. of Appl. Psych. 78 715-722.

Basil, D. Z., Ridgway, N. M., \& Basil, M. D. 2008. Guilt and giving: A process model of empathy and efficacy. Psych. \& Marketing 25 1-23.

Baumeister, R. F., Stillwell, A. M., \& Heatherton, T. F. 1994. Guilt: An Interpersonal Approach. Psych. Bull. 115 243-267.

Beck, A.T. (1970). Depression: Causes and Treatments. Philadelphia: University of Pennsylvania Press. 
Benedict R. 1946. The Chrysanthemum and the Sword. Boston: Houghton Mifflin.

Bitner, M. 1990. Evaluating service encounters: The effects of physical surroundings and employee responses. J. Marketing 55 69-82.

Blaine B, Crocker J. 1993. Self-esteem and self-serving biases in reactions to positive and negative events: an integrative review. In Self-Esteem: The Puzzle of Low Self-Regard, ed. RF Baumeister, pp. 55-85. New York: Plenum.

Blau, P. M. 1960 Structural Effects. Amer. Soc. Rev. 25 178-193.

Bohns, V. K., Handgraaf, M. J. J., Sun, J. M., Aaldering, H., Mao, C., \& Logg, J. 2011. Are social prediction errors universal? Predicting compliance with a direct request across cultures. $J$. Experimental Soc. Psych. 47 676-680.

Brockner, J., Davy, J., \& Carter, C. 1986. Layoffs, self-esteem, and survivor guilt: Motivational, affective, and attitudinal consequences. Org. Behav. Human Dec. Proc. 36 229-244.

Brockner, J., Greenberg, J., Brockner, A., Bortz, J., Davy, J., \& Carter, C. 1986. Layoffs, equity theory, and work performance: Further evidence of the impact of survivor guilt. Acad. Management J. $29373-384$.

Butler, R. \& Nisan, M. 1986. Effects of no feedback, task-related comments, and grades on intrinsic motivation and performance. J. Educ. Psych. $\mathbf{7 8} 210-216$.

Campion, M. A., Cheraskin, L., Stevens, M. G. 1994. Career-related antecedents and outcomes of job rotation. Acad. Management J. 37 1518-1542.

Carver, C. S. \& Scheier, M. F. (1990). Origins and Functions of Positive and Negative Affect: A ControlProcess View. Psych. Rev. 97 19-35.

Chodoff, P., Friedman, S. B., \& Hamburg, D. A. 1964. Stress defenses and coping behavior: Observations 
in parents of children with malignant disease. Amer. J. Psychiatry 120 743-749.

Cohen, S., Rothbart, M. \& Phillips, S. 1976. Locus of control and the generality of learned helplessness in humans. J. Pers. and Soc. Psych. 34 1049-1056.

Covert, M. V., Tangney, J. P., Maddux, J. E., \& Heleno, N. M. 2003. Shame-proneness, guilt-proneness, and interpersonal problem solving: A social cognitive analysis. J. Soc. and Clinical Psych. 22 112.

Cunningham, M. R., Steinberg, J. \& Grev, R. 1980. Wanting to and having to help: Separate motivations for positive mood and guilt-induced helping. J. Pers. and Soc. Psych. 38 181-192.

Davis, K. 1997. Human behavior at work: Organizational behavior, $5^{\text {th }}$ ed. New York: McGraw-Hill.

Davis-Blake, A. \& Pfeffer, J. 1989. Just a mirage: The search for dispositional effects in organizational research. Acad. Management Rev. 14 385-400.

de Hooge, I. E., Zeelenberg, M. \& Breugelmans, S. M. 2007. Moral sentiments and cooperation: Differential influences of shame and guilt. Cognition and Emotion 21 1025-1042.

Dickerson, S. S., Gruenewald, T. L. \& Kemeny, M. E. 2004. When the social self is threatened: Same, physiology, and health. J. Personality 72 1192-1216.

Diener, C. I. \& Dweck, C. S. 1980. An analysis of learned helplessness: The processing of success. J. Pers. and Soc. Psych. 39 940-952.

Edwards, J. R. 1992. A cybernetic theory of stress, coping, and well-being in organizations. Acad. Management Rev. 17 238-274.

Elfenbein, H. A. 2007. Emotion in organizations: A Rev. and theoretical integration. Acad. Management Ann. $1371-457$. 
Fisher, C. D. 1979. Transmission of positive and negative feedback to subordinates: A laboratory investigation. J. Appl. Psych. 64 533-540.

Flynn, F. J. \& Schaumberg, R. L. 2012. When feeling bad leads to feeling good: Guilt-proneness and affective organizational commitment. J. Appl. Psych, 97, 124-133.

Freedman, J. L. Wallington, S. A. \& Bless, E. 1967. Compliance without pressure: The effect of guilt. J. Pers. and Soc. Psych. 7 117-124.

Frijda, N. H. 1986. The emotions: Studies in emotion and social interaction. New York: Cambridge University Press.

Geen, R. \& Berkowitz, L. 1967. Some conditions facilitating the occurrence of aggression after the observation of violence. J. Personality 35 666-676.

Gellatly, I. R. 1996. Conscientiousness and task performance: Test of a cognitive process model. J. Appl. Psych. 81 474-482.

George, J. M. 1991. State or trait: effects of positive mood on prosocial behaviors at work. J. Appl. Psych. 76 299-307.

George, J. M. \& Brief, A. P. 1996. Motivational agendas in the workplace: The effects of feelings on focus of attention and work motivation. In B. M. Staw \& L.L. Cummings (Eds.) Research in organizational behavior: An annual series of analytical essays and critical Rev.s, Vol. 18 (pp. 75-109). US: Elsevier Sci./JAI Press.

Hackman, J. R. 1980. Work redesign and motivation. Professional Psych.: Research and Practice $11445-455$.

Hackman, J. R. \& Oldham, G. R. 1976. Motivation through the design of work: Test of a theory. 
Organ. Behav. and Human Perform. 16 250-279.

Hackman, J. R. \& Oldham, G. R. 1980. Work Redesign. Addison-Wesley: Reading, MA.

Haidt, J. 2003. The moral emotions. In R. J. Davidson, K.R. Scherer, \& H.H. Goldsmith (Eds.)

Handbook of affective sciences. 852-870. Oxford: Oxford University Press.

Harris, S. G. 1994. Organizational culture and individual sensemaking: A schema-based perspective.

Organ. Science. 5 309-321.

Heine, S. J., Takemoto, T., Moskalenko, S., Lasaleta, J., \& Henrich, J. 2008. Mirrors in the head:

Cultural variation in objective self-awareness. Pers. and Soc. Psych. Bull. 34 879-887.

Hibbert, S., Smith, A., Davies, A. \& Ireland, F. 2007. Guilt appeals: Persuasion knowledge and charitable giving. Psych. and Marketing 24 723-742.

Horney, K. 1937. The neurotic personality of our time. New York: Norton.

Illies, R. \& Judge, T. A. 2005. Goal regulation across time. J. Appl. Psych. 90 453-467.

Ilgen, D. R. \& Knowlton, W. A. 1980. Performance attributional effects on feedback from superiors. Organ. Behav. And Human Performance 25 441-456.

Isen, A. M. \& Baron, R. A. 1991. Positive affect as a factor in organizational behavior. Res. in Organ. Behav. 13 1-53.

Izard, C. (1977). Human Emotions. Plenum Press: New York.

James, W. 1884. What is an emotion? Mind 9 188-205.

Keltner, D. \& Buswell, B. N. Embarrassment: Its distinct form and appeasement functions. Psych. Bull. 122 250-270.

Keltner, D., Locke, K. D. \& Audrain, P. C. 1993. The influence of attributions on the relevance of 
negative feelings to personal satisfaction. Pers. and Soc. Psych. Bul. 19 21-29.

Ketelaar, T. \& Au, W. T. 2003. The effects of guilty feelings on the behavior of uncooperative individuals in repeated and Soc. bargaining games: An affect-as-information interpretation of the role of emotion in Soc. interaction. Cognition and Emotion 17 429-453.

Kluger, A. \& DeNisi, A. 1996. The effects of feedback interventions on performance: A historical review, a meta-analysis, and a preliminary feedback intervention theory. Psych. Bull. 119 254-284.

Kochanska, G., \& Thompson, R.A. 1997. The emergence and development of conscience in toddlerhood and early childhood. In J.E. Grusec \& L. Kuczynski (Eds.), Parenting and children's internalization of values: A handbook of contemporary theory (pp. 53-77). New York: Wiley.

Konecni, V. J. 1972. Some effects of guilt on compliance: A field replication. J. Pers. and Soc. Psych. 23 30-32.

Kugler, K. \& Jones, W. H. 1992. On conceptualizing and assessing guilt. J. Pers. and Soc. Psych. 62 318-327.

Lagattuta, K. H., \& Thompson, R. A. 2007. The development of self-conscious emotions: Cognitive processes and social influences. In J.L. Tracy, R.W. Robins, \& J. P. Tangney (Eds.), The selfconscious emotions: Theory and research (pp. 91-113). New York: Guilford.

Langer, E. J. 1975. The illusion of control. J. Pers. and Soc. Psych. 32 311-328.

Langer, E. J. and Saegert, S. 1977. Crowding and cognitive control. J. Pers. and Soc. Psych 35 175-182.

Langred, C. W. \& Moye, N. A. 2004. Effects of task autonomy on performance: An extended model considering motivational, informational, and structural mechanisms. J. Appl. Psych. 89 934-945.

Larson, J. R. 1986. Supervisors' performance feedback to subordinates: The impact of subordinate performance valence and outcome dependence. Organ. Behav. Human Dec. Proc. 37 
391-408.

Larson, J. R. 1989. The dynamic interplay between employees' feedback-seeking strategies and supervisors' delivery of performance feedback. Acad. Management Rev. 14 408-422.

Lazarus, R. S. 1991. Emotion \& Adaptation. New York: Oxford University Press.

Lazarus, R. S. \& Folkman, S. 1984. Stress, appraisal, and coping. New York: Springer.

Leary, M. R. 2007. Motivational and Emotional Aspects of the Self. Ann. Rev. Psych. 58 317-44.

Leith, K. P. \& Baumeister, R. F. 1998. Empathy, shame, guilt, and narratives of interpersonal conflicts: Guilt-prone people are better at perspective-taking. J. Personality 66 1-37.

Lewis, H. B. 1987. Shame and the narcissistic personality. In D. L. Nathanson (Ed.), The many faces of shame (pp. 93-132). New York: Guilford Press

Lewis, H. B. 1971. Shame and guilt in neurosis. Madison, CT: International Universities Press.

Lindsey, L. L. M., Yun, K. A. \& Hill, J. B. (2007). Anticipated guilt as motivation to help unknown others: An examination of empathy as a moderator. Communication Res. 34 468-480.

Lindsay-Hartz, J., de Rivera, J. \& Mascolo, M. 1995. Differentiating guilt and shame and their effects on motivation. In Tangney and K. W. Fisher (Eds.) Self-conscious emotions: Pride, shame, guilt, and embarrassment. New York: Guilford Press.

Luthans, F. \& Kreitner, R. 1985. Organizational behavior modification and beyond: An operant and social learning approach. London, England: Scott Foresman \& Co.

Lyubomirsky, S., King, L., \& Diener, E. 2005. The benefits of frequent positive affect: Does happiness lead to success? Psych. Bull. 131 803-855.

Manstead, A. \& Tetlock, P. E. 1989. Cognitive appraisals and emotional experience: Further evidence. 


\section{Cognition and Emotion 3 225-240.}

Martocchio, J. J. \& Judge, T. A. 1997. Relationship between conscientiousness and learning in employee training: Mediating influences of self-deception and self-efficacy. J. Appl. Psych. 82 764-773.

McLean, B. \& Elkind, P. 2003. The Smartest Guys in the Room: The amazing rise and scandalous fall of Enron. New York: Portfolio.

McArthur, L. Z. \& Post, D. L. 1977. Figural emphasis and person perception. J. Experiment. Soc. Psych. 13 520-535.

McColl-Kennedy, J. R. \& Anderson, R. D. 2002. Impact of leadership style and emotions on subordinate performance.Leadership Quarterly. 13 545-559.

Miller, D. 1976, Ego-Involvement and Attributions for Success and Failure. J. Pers. and Soc. Psych. 34 901-906.

Moon, H. 2001. The two faces of conscientiousness: Duty and achievement striving in the escalation of commitment dilemmas. J. Appl. Psych. 86 533-540.

Moorman, R. H. \& Blakely, G. L. 1995. Individualism-collectivism as an individual difference predictor of organizational citizenship behavior. Journal Org. Behav. 16 127-142.

Mowrer, O. H. 1960. Learning theory and behavior. Hoboken, NJ: John Wiley \& Sons.

Mueller, C. M. \& Dweck, C. S. 1988. Intelligence praise can undermine motivation and performance. $J$. Pers. and Soc. Psych. 75 33-52.

Nussbaum, S., Trope, Y., \& Liberman, N. 2003. Creeping dispositionism: The temporal dynamics of behavior prediction. J. Pers. and Soc. Psych. 84 485-497.

O’Connor, L.E., Berry, J.W., \& Weiss, J. 1999. Interpersonal guilt, shame, and psychological problems. J. of Soc. and Clinical Psych. 18 181-203. 
Pearce, J. L. \& Porter, L. W. 1996. Employee Responses to Formal Performance Appraisal Feedback. J. Appl. Psych. 71 211-218.

Pham, L. B., \& Taylor, S. E. 1999. From thought to action: Effects of process- versus outcome-based mental simulations on performance, Pers. and Soc. Psych. Bull. 25 250-26

Pizarro, D. A. \& Bloom, P. 2003. The intelligence of the moral intuitions: A comment on Haidt (2001). Psych. Rev. 110 193-196.

Riess, M. \& Taylor, J. 1984. Ego-Involvement and Attributions for Success and Failure in a Field Setting Pers. and Soc. Psych. Bull. 10 536-543

Roseman, I. J. 1991. Appraisal determinants of discrete emotions. Cognition and Emotion 5 161-200.

Roseman, I. J., Spindel, M. S. \& Jose, P. E. 1990. Appraisals of emotion-eliciting events: Testing a theory of discrete emotions. J. Pers. and Soc. Psych. 5 899-915.

Rotter, J. B. 1966. Generalized expectancies for internal versus external control of reinforcement. Psych. Monographs: General and Appl. 80 1-28.

Salancik, G. R. \& Pfeffer, J. 1978. A social information processing approach to job attitudes and task design. Admin. Sci. Quart. 23 224-253.

Schachter, S. \& Singer, J. 1962. Cognitive, Soc., and physiological determinants of emotional state. Psych. Rev. 69 379-399.

Schaumberg, R. \& Flynn, F. 2012. Uneasy lies the head that wears a crown: The link between guiltproneness and leadership. J. Pers. and Soc. Psych.

Schwarz, N. \& Clore, G. L. (1983). Mood, Misattribution, and Judgments of Well-Being: Informative and Directive Functions of Affective States. J. Pers. and Soc. Psych. 45 513-523. 
Scheff, T. J. 1987. The shame/rage spiral: Case study of an interminable quarrel. In H. B. Lewis (Ed.)'s The Role of Shame in Symptom Formation. Hillsdale, NJ: Lawrence Erlbaum.

Seligman, M. E. P. 1975. Helplessness: On depression, development, and death. New York, NY: W. H. Freeman.

Seligman, M. E. P. \& Maier, S. E. 1967. Failure to escape traumatic shock. J. Exper. Psych. 74 1-9.

Semin, G. R. \& Manstead, A. 1982. The social implications of embarrassment displays and restitution behavior. European J. Soc. Psych. 12 367-377.

Seo, M., Feldman Barrett, L., \& Bartunek, J. 2004. The role of affective experience in work motivation. Acad. Management Rev. 29 423-439.

Sheperd, D. A., Patzelt, H. \& Wolfe, M. 2011. Moving forward from project failure: Negative emotions, affective commitment, and learning from the experience. Acad. Management J. 54 1129-1259.

Sherrod, D. R. 1974. Crowding, perceived control, and behavioral after- effects. J. Appl. Soc. Psych. 4 171-186.

Sherrod, D. R., Hage, J. N., Halpem, P. L., \& Moore, B. S. 1977. Effects of personal causation and perceived control on responses to an aversive environment: The more control, the better. $J$. Experiment. Soc. Psych. 13 14-27.

Silfver, M., Helkama, K., Lonngvist, J., \& Verkasalo, M. 2008. The relation between value priorities and proneness to guilt, shame, and empathy. Motivation and Emotion 32 69-80.

Smith, G. M. 1967. Usefulness of peer ratings of personality in educational research. Ed. and Psych. Measurement 27 967-984.

Smith, R. H., Webster, M. J., Parrott, G. W., \& Eyre, H. L.2002. The role of public exposure in moral and 
nonmoral shame and guilt. J. Pers. and Soc. Psych. 83 138-159.

Spector, P. E. 1975. Relationships of organizational frustration with reported behavioral reactions of employees. J. Appl. Psych. 60 635-637.

Staw, B. M., Bell, N. E., \& Clausen, J. A. 1986. The dispositional approach to job attitudes: A lifetime longitudinal test. Admin. Sci. Quart. 31 56-77.

Stipek, D. 1995. The development of pride and shame in toddlers. In J. P. Tangney \& K.W. Fischer (Eds.), Self-conscious emotions: The psychology of shame, guilt, embarrassment, and pride (pp. 237-252). New York: Guilford Press.

Stipek, D. 1998. Differences between Americans and Chinese in the Circumstances Evoking Pride, Shame, and Guilt. J. Cross-Cultural Psych. 29 616-629.

Tangney, J. P. 1990. Assessing individual differences in proneness to shame and guilt: Development of the Self-Conscious Affect and Attribution Inventory. J. Pers. and Soc. Psych. 59 102111.

Tangney, J. P. 1991. Moral affect: The good, the bad, and the ugly. J. Pers. and Soc. Psych. 61 598-607.

Tangney, J. P. 1992. Situational determinants of shame and guilt in young adulthood. Pers. and Soc. Psych. Bull. 18 199-206.

Tangney, J. P. 1995. Shame and guilt in interpersonal relationships. In J. P. Tangney \& K. W. Fischer (Eds.), Self-conscious emotions: Shame, guilt, embarrassment, and pride. (pp. 114-139). New York: Guilford.

Tangney, J. P. \& Dearing, R. L. 2002. Shame and Guilt. New York: Guilford Press. 
Tangney, J. P., Stuewig, J., \& Mashek, D. 2007. Moral emotions and moral behavior. Annual Rev. Psych. 58 345-372.

Tangney, J. P., Wagner, P., Fletcher, C., \& Gramzow, R. 1992. Shamed into anger? The relation of shame and guilt to anger and self-reported aggression. J. Pers. and Soc. Psych. 62 669675.

Tangney, J. P., Wagner, P., \& Gramzow, R. 1989. The Test of Self-Conscious Affect. Fairfax, VA: George Mason University.

Tangney, J. P., Wagner, P. E., Hill-Barlow, D., Marschall, D. E., \& Gramzow, R. 1996. Relation of shame and guilt to constructive versus destructive responses to anger across the lifespan. J. Pers. and Soc. Psych. 70 797-809.

Taylor, S. E., \& Schneider, S. K. 1989. Coping and the simulation of events. Soc. Cognition 7 174-194

Tracy, J. L. \& Robins, R. W. 2006. Appraisal Antecedents of Shame and Guilt: Support for a Theoretical Model. Personality and Soc. Psych. Bull. 32 1339-1351.

Trope, Y. 1989. Levels of inference in dispositional judgment. Soc. Cognition 7 296-314.

Trope, Y, \& Liberman, N. 2003. Temporal construal. Psych. Rev. 110 403-421.

Verbeke, W. \& Bagozzi, R. P. 2002. A situational analysis on how salespeople experience and cope with shame and embarrassment. Psych. \& Marketing 19 713-741.

Vroom, V. H. 1964. Work and Motivation. New York: Wiley.

Wageman, R. 1995. Interdependence and group effectiveness. Admin. Sci. Quart. 40 145-180.

Wallbott, H. G. \& Scherer, K. R. 1995. Cultural determinants in experiencing shame and guilt. In Tangney, June Price (Ed); Fischer, Kurt W. (Ed), Self-conscious emotions: The psychology of shame, guilt, embarrassment, and pride, (pp. 465-487). New York: Guilford Press. 
Wastell, C. \& Booth, A. 2003. Machiavellianism: An alexithymic perspective. J. Soc. and Clinical Psych. 22 730-744.

Watkins, E., \& Teasdale, J. D. 2001. Rumination and overgeneral memory in depression: effects of selffocus and analytic thinking. J. Abnormal Psych.110 353-357.

Weiner, B. 1985. Spontaneous causal thinking. Psych. Bull. 97 74-84.

Weiss, H.M. \& Cropanzano, R. 1996. Affective events theory: a theoretical discussion of the structure, causes, and consequences of affective experiences at work. Res. Organ. Behav. 18 1-74.

Wiggins, N., Blackburn, M., \& Hackman, J. R. 1969. Prediction of first-year graduate success in Psychology: Peer ratings. J. Ed. Research 63 81-85.

Wilkins, A. L., \& Ouchi, W. G. 1983 Efficient cultures: Exploring the relationship between culture and organizational performance. Admin. Sci. Quart. 28 468-481.

Williams, L. E. \& Bargh, J. 2008. Keeping one's distance: The influence of spatial distance cues on affect and evaluation. Psych. Sci. 19 302-308.

Williamson, I., Sandage, S. J., \& Lee, R. M. 2007. How social connectedness affects guilt and shame: Mediation by hope and differentiation of self. Pers. \& Indiv. Differences 43 2159-2170.

Woien, S. L., Ernst, H. A. H., Patock-Peckham, J. A. \& Nagoshi, C. T. 2003. Validation of the TOSCA to measure guilt and shame. Pers. and Indiv. Differences 35 313-326.

Wortman, C. B. 1975. Some determinants of perceived control. J. Pers. Soc. Psych. 31 282-294.

Wright, T. A. \& Staw, B. M. 1999. Affect and favorable work outcomes: Two longitudinal tests of the happy-productive worker thesis. J. Organ. Behav. 20 1-23.

Zeelenberg, M. \& Breugelmans, S. M. 2008. The role of interpersonal harm in distinguishing regret from guilt. Emotion 8 589-596. 
FIGURE 1.

Eliciting guilt in response to performance failure in organizations. 
Guilt by Design 2 

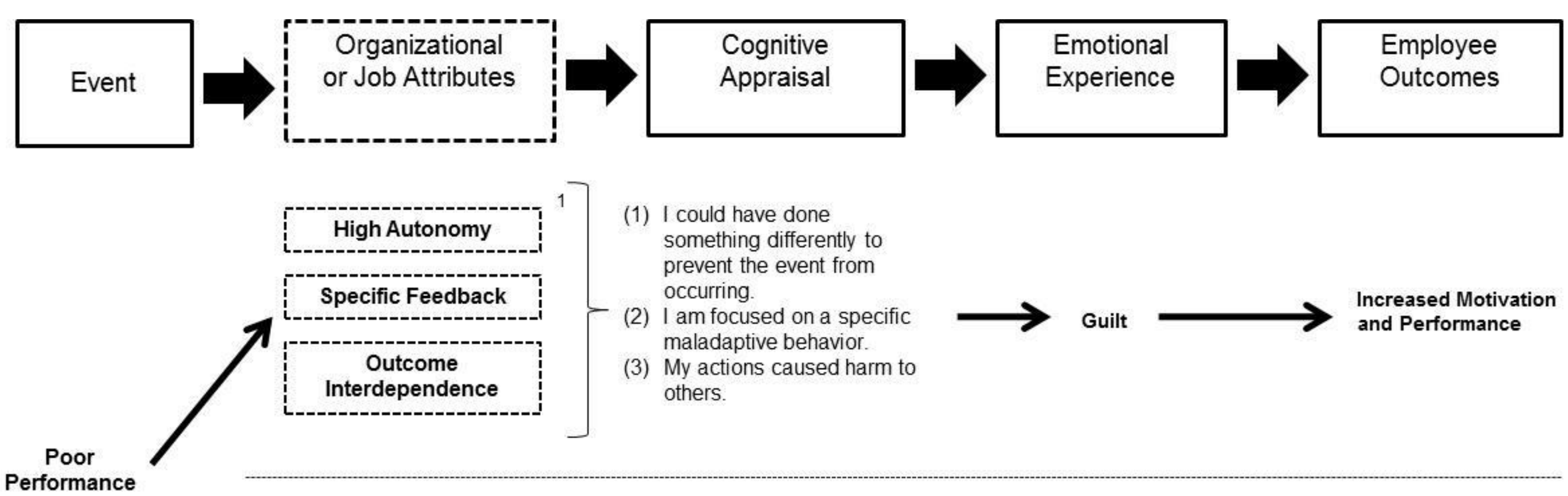

Performance

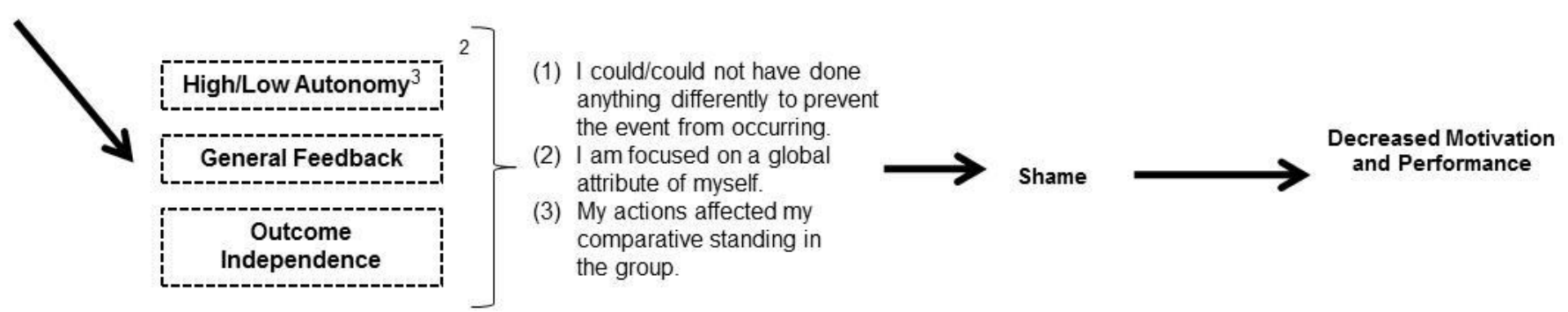

${ }^{1}$ Example: A salesperson who has authority to negotiate over the terms of his or her product, and is given feedback in the form of detailed analyses of his or her sales calls, in an organization that gives bonuses for reaching collective sales milestones.

${ }^{2}$ Example: A salesperson who does not have authority to negotiate over the terms of his or her product, and is given feedback in the form of weekly employee sales rankings, in an organization that gives bonuses for reaching individual sales milestones.

${ }^{3}$ Although greater autonomy should increase the likelihood that an employee will experience guilt in response to failure, it will not necessarily increase or decrease the likelihood of experiencing shame. The attribution that one had control over a negative outcome (which results from high autonomy in the model) is orthogonal to shame. 